\title{
Growth and Physiological Response of Fraser Fir [Abies fraseri (Pursh) Poir.] Seedlings to Water Stress: Seasonal and Diurnal Variations in Photosynthetic Pigments and Carbohydrate Concentration
}

\author{
Şemsettin Kulaç ${ }^{1}$ \\ Department of Forestry, Düzce University, 81620 Düzce, Turkey
}

Pascal Nzokou ${ }^{2,4}$

Department of Forestry, Michigan State University, 480 Wilson Road, Natural Resources Building, Room 126, East Lansing, MI 48824

Deniz Guney ${ }^{1}$

Department of Forestry, Karadeniz Technical University, 61080 Trabzon, Turkey

Bert Michael Cregg ${ }^{2}$

Department of Horticulture and Forestry, Michigan State University, A214

Plant and Soil Sciences Building, East Lansing, MI 48824

\section{Ibrahim Turna ${ }^{3}$ \\ Department of Forestry, Karadeniz Technical University, 61080 Trabzon, Turkey}

Additional index words. carotenes, chlorophyll pigments, drought, photosynthesis, total chlorophyll, D-glucose, stem water potential

\begin{abstract}
Four-year-old seedlings of Abies fraseri [(Pursh) Poir] (fraser fir) were grown in semicontrolled conditions in hoop houses with five watering regimes $(0.00,0.62,1.25,2.50$, and $3.70 \mathrm{~cm} /$ week) with the goal of determining the seasonal variation in the physiological response to drought stress. Drought stress was monitored by measuring predawn $(\Psi \mathrm{pd})$ and midday ( $\Psi \mathrm{md})$ potentials in a subset of plants from each treatment. Physiological variables monitored were chlorophyll fluorescence $\left(F_{\mathrm{v}} / F_{\mathrm{m}}\right), \mathrm{Chl}$ a, $\mathrm{Chl} \mathrm{b}$, total carotenes, and total carbohydrate concentrations. Morphological characteristics including height growth, root collar diameter, and terminal shoot growth were also measured. Predawn stem water potential values were generally higher $(-0.8$ to $-1.9 \mathrm{Mpa})$ than midday values ( -1.3 to $-2.9 \mathrm{Mpa})$. Irrigation consistently increased $\Psi$ pd and $\Psi$ md compared with nonirrigated treatments. Photosynthetic pigments ( $\mathrm{Chl}$ a, $\mathrm{Chl}$ b, and carotenes) decreased midseason (14 July) and increased toward the end of the season (25 Aug.) in predawn and midday measurements. There was a significant effect $(P<0.05)$ of drought stress on photosynthetic pigment concentrations in predawn and midday samples in the late-season measurements (25 Aug.). These results were accompanied with a similar significant difference in $F_{\mathrm{v}} / F_{\mathrm{m}}$ between non-irrigated and irrigated trees. We concluded that significant effects observed on photosynthetic pigment concentrations in some of the treatments did not affect carbohydrate concentrations. Exposure of $A$. fraseri to water stress did not cause a reduction in supply of metabolic carbohydrates; consequently, the decline and mortality in water-stressed plants can only be the result of hydraulic failure caused by xylem cavitation leading to cessation of water flow in tissues, desiccation, and cellular death. Further studies are needed to confirm these preliminary conclusions.
\end{abstract}

Fraser fir [Abies fraseri (Pursh) Poir.] is widely planted for Christmas tree production in the midwest and eastern United States. The

\footnotetext{
Received for publication 7 June 2012. Accepted for publication 14 Aug. 2012.

${ }^{1}$ Assistant Professor.

${ }^{2}$ Associate Professor.

${ }^{3}$ Professor

${ }^{4}$ To whom reprint requests should be addressed; e-mailnzokoupa@msu.edu.
}

planting this species under summer drought stress-susceptible conditions are not well understood.

Drought stress is characterized by reduction of water content, increased closure of stomata, and decrease in cell enlargement and growth. Severe water stress may result in the arrest of photosynthesis, progressive suppression of photosynthetic carbon assimilation, disturbance of metabolism, and finally the death of the plant (Deltoro et al., 1998; Jaleel et al., 2008). After stomatal closure, there is a decrease in $\mathrm{CO}_{2}$ intake and intercellular $\mathrm{CO}_{2}$ partial pressure, thereby a reduction in $\mathrm{CO}_{2}$ assimilation and net photosynthesis (Deltoro et al., 1998; Dubey 1997; Farquhar et al., 2001). Stomatal closure is the result of either hydropassive or hydroactive mechanisms (Dubey, 1997). In the hydropassive mechanism, guard cells loose water so rapidly that the loss cannot be balanced by water movement from adjacent cells (Shope et al., 2008). In the hydroactive mechanism, stomatal closure is the result of the reduction in stored abscisic acid from the mesophyll chloroplast to the apoplasts (Hartung, 1983). In addition, the rate of $\mathrm{CO}_{2}$ assimilation is depressed at very moderate water deficits or even before the plant's water status changes in response to the drop in water pressure deficit (Bunce, 1981) or soil potential (Gollan et al., 1986). Therefore, it can be expected that diurnal changes in plant water potential caused by daily variation associated with environmental conditions will interact with water stress to affect the photosynthetic system. Direct consequences of these processes are inhibition of cell expansion, which adversely affects crop growth and yield. On the other hand, water stress causes ultrastructural changes in the chloroplasts that adversely affect photosynthesis (Dubey, 1997). Under drought stress, contents of photosyn-

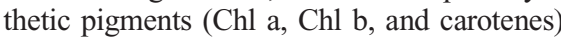
diminish (Pukacki and Kaminska-Rozek, 2005; Terzi et al., 2010; Yordanov et al., 2000). For example, in fully active leaves of Xerophyta scabrida submitted to drought stress, the $\mathrm{CO}_{2}$ assimilation, thylakoid activity, and respiration rate declined, whereas chlorophyll and carotene contents were successively broken down (Deltoro et al., 1998). When drought coincided with high radiation, it led to a decrease in carotenoid content in evergreen woody species Quercus ilex, Quercus coccifera, Pinus halepensis, and Juniperus phoenicea (Baquedano and Castillo, 2007).

However, photosynthetic systems have the ability to recover from drought stress when water becomes available (Nar et al., 2009). This process involves a complex of signals comprising metabolites produced during rehydration. For example, re-accumulation of $\mathrm{Chl}(\mathrm{a}+\mathrm{b})$ and carotenoid synthesis was observed in stressed plants once leaves reached $\approx 91 \%$ of the maximum leaf water content (Schwab et al., 1989; Tuba et al., 1996). This underscores the need to understand not only diurnal patterns, but also seasonal changes in photosynthetic pigments caused by variations in stress conditions that 
plants are subjected to during a growing season.

Another possible physiological response to drought stress is the alteration in the synthesis of both starch and sucrose in stressed plants (Vassey and Sharkey, 1989). Impairment of photosynthesis resulting from drought stress can result in the utilization rate of photosynthates exceeding their production rates, thus making carbon and energy metabolism dependent on non-structural carbohydrate reserves (Guehl et al., 1993). However, in some species, drought can enhance carbohydrate accumulation (Guehl et al., 1993; Thomas, 1990). In that situation, the increase in soluble sugars in response to water stress can be attributed to less translocation from the leaf, slower consumption resulting from decreased growth, and other changes such as starch hydrolysis (Kameli and Losel, 1996).

We are hypothesizing that under increased drought conditions, trees will respond by decreasing their photosynthetic abilities resulting from stomatal closure, leading to a decrease in quantities of photosynthates produced. We also expect diurnal variation with a midday depression in measurements resulting from environmental conditions. The aim of this study was to determine diurnal and seasonal patterns in photosynthetic pigments ( $\mathrm{Chl} \mathrm{a}, \mathrm{Chl} \mathrm{b}$, carotenes), carbohydrate accumulation, and growth of Abies fraseri under controlled drought stress created by varying irrigation regimes. The results of this study could help in understanding the drought tolerance and adaptation potential of this species to drought-prone environments.

\section{Material and Methods}

The study was conducted in four hoop houses running east to west at the Tree Research Center (lat. $42.65^{\circ} \mathrm{N}$, long. $84.42^{\circ}$ $\mathrm{W})$ on the campus of Michigan State University. The hoop houses were designed to keep rain from falling directly on to treatment plots. Each house was divided into five sections containing the various treatments by waterproof dividers (oriented strandboard wrapped with a plastic cover) inserted about $1 \mathrm{~m}$ into the ground to prevent lateral movement of soil moisture. All hoop houses were open at both ends and $15 \mathrm{~cm}$ from the ground on both sides to allow free airflow and avoid rises in temperatures as a result of a greenhouse effect. This process was successful, although inside air temperatures were only 1 or $2{ }^{\circ} \mathrm{C}$ higher than outside temperatures in the middle of very warm days.

Each of the hoop house sections was randomly assigned one of the five irrigation treatments with all five treatments replicated in each of the four hoop houses (blocking) in a randomized complete block design. Each plot was physically separated from the adjacent plot by 2 feet wide 3/4-inch board wrapped with a plastic cover to prevent lateral movement of moisture and maintain the integrity of each irrigation treatment. These boards were vertical inserted between plot boundaries before the experiment began. Water was supplied during the growing season (10 May to 30 Aug. 2009) through an irrigation system equipped with Uniram ${ }^{\mathrm{TM}}$ (1.55 $\mathrm{cm}$ i.d. and $1.1 \mathrm{~mm}$ wall thickness) drip line manufactured by Netafim ${ }^{\mathrm{TM}}$ (Netafilm Irrigation Inc., Fresno, CA). The drip emitters used were equipped with pressure regulators to deliver $1.6 \mathrm{~L}$ per hour $(0.42$ gallon per hour) and spaced $60 \mathrm{~cm}$ (24 inches) apart. The irrigation system was fully automated and operated by an ACCLIMA SC 24 controller (Acclima Inc., Meridian, ID). One digital time domain reflectometry moisture sensor model ACC-SEN-TDR (Acclima Inc.) was inserted in each treatment for monitoring of soil moisture content and soil temperatures. Variability in soil moisture content and soil temperature from midday readings obtained from soil moisture sensor readings confirmed clear differences between irrigated and non-irrigated treatments (Fig. 1).

The layout and tubing were designed to simultaneously apply water to all four replicate plots for each irrigation level $(0,0.62$, $1.25,2.5$, and $3.75 \mathrm{~cm} /$ week). Irrigation depths were calculated using the emitter flow rate, the area covered by each emitter, and the run time controlled by the controller. These irrigation depths correspond to $0,12,18,25$, and 38 min of run time per day applied $7 \mathrm{~d}$ a week.

Plant materials used were Abies fraseri transplants (plug +2$)$ obtained from a commercial nursery and installed in the field in the spring of 2008. The average size of these plants at the beginning of the 2009 growing season was $45.6 \mathrm{~cm}$ and $17.4 \mathrm{~mm}$ for height and diameter, respectively. Trees were fertilized at the rate of $56 \mathrm{~kg} \cdot \mathrm{ha}^{-1}$ using ammonium sulfate manually broadcasted at the beginning of the growing season in each plot. Weeds were controlled by hand or by applying glyphosate at a rate of $35.84 \mathrm{~kg} \cdot \mathrm{ha}^{-1}$ using a $\mathrm{CO}_{2}$-powered backpack sprayer to keep fraser fir transplants weed-free.

Each plot had four rows of trees containing seven trees in $0.6-\mathrm{m}$ spacing (28 trees total per plot). The two outermost trees in each row were used as a buffer against edge effects and not measured, leaving a total of 20 trees per plot for a total of 400 plants for measurement purposes.
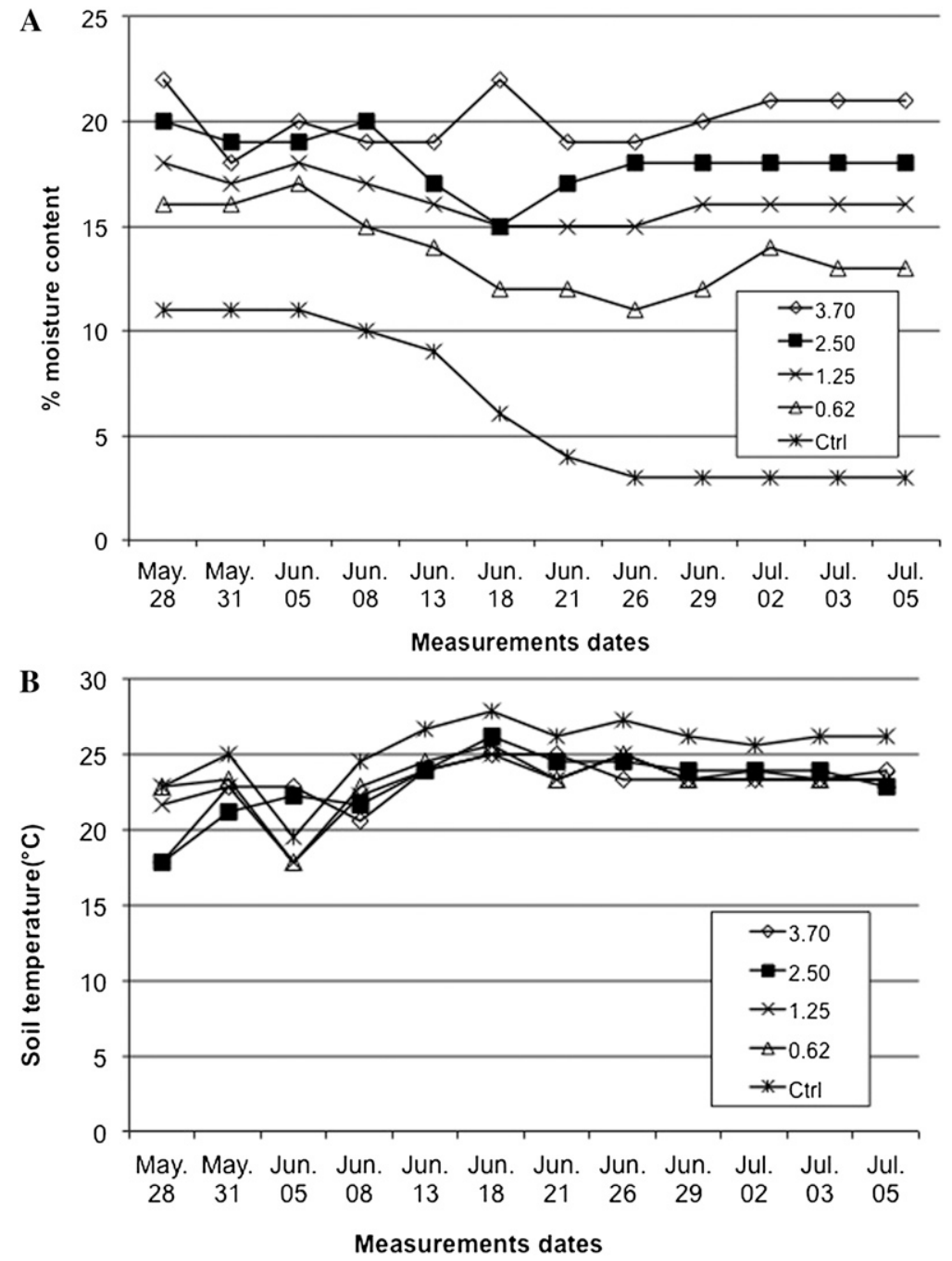

Fig. 1. Changes in soil moisture content (A) and soil temperature (B) over 12 sampling dates (twice a week) from 27 May and 7 July. 
Water potential measurement. Five representative trees (100 total for all plots) in each plot were selected for water potential measurements. The trees were flagged and all measurements conducted on the same group of trees in each plot for each sampling date. Predawn and midday water potentials were determined once every 2 weeks between 2 June and 25 Aug. in cut branches using the pressure chamber method with a plant water status console Model 3115 (Soil Moisture Equipment Corp., Santa Barbara, CA) according to Turner (1988). Predawn water potential was measured between 0400 and $0600 \mathrm{HR}$, whereas midday measurement was done between 1200 and $1400 \mathrm{HR}$. Cuttings of $\approx 5$ to $7 \mathrm{~cm}$ collected from the current year's growth were taken from the upper part of each plant. Each clipping was promptly placed in the pressure chamber to prevent dehydration of the sample and their stem water potential measured. Each branch was placed in the pressure chamber; then the chamber was pressurized and on the reading taken when using a magnifying glass we could see that the cut stem surface was wet or shiny, an indication of xylem water coming back to the surface.

Growth measurements. Height growth and root collar diameter of all seedlings were measured before water stress treatments started on 20 May 2009. Subsequently, growth measurements were conducted once a month until 2 Sept. 2009.

Height and diameter growth were calculated as the difference between the final and initial measurements. The height growth was normalized to relative height growth (RHG) by dividing each seasonal change in height by the initial height as follows:

$$
R H G=\Delta H / \Delta t^{*} 1 / H i
$$

where $\Delta H / \Delta t$ is the change in height over the growing season and $\mathrm{Hi}$ is the initial height of the specimen.

The same procedure was used to adjust changes in diameter growth into relative root collar diameter.

Photosynthetic pigment determination. Photosynthetic pigments were determined spectrophotometrically and calculated according to procedures described by several authors (Nar et al., 2009; Ribeiro et al., 2009; Wellburn et al., 1983) summarized as follows. Fresh needle samples $(0.1 \mathrm{~g})$ were randomly selected from plants and homogenized in a mortar with a pestle in $80 \%$ acetone. The extract was centrifuged at $5000 \mathrm{rpm}$ for $5 \mathrm{~min}$. Aliquots of supernatants were transferred into appropriate cuvettes and the absorbance was measured at 450, 645, and $663 \mathrm{~nm}$ with a Hewlett Packard 8452A photodiode array ultraviolet/Vis spectrophotometer (Agilent Technologies, Santa Clara, CA). Acetone $(80 \%)$ was used as blank. Photosynthetic pigments were determined on both predawn and midday samples, and the concentrations of Chls and carotenoids were expressed in $\mathrm{mg} \cdot \mathrm{g}^{-1}$ of fresh foliar weight.

Carbohydrate content. Foliage carbohydrate concentrations for samples collected during the predawn and midday stem water potential measurements were estimated by the phenol-sulfuric acid method (Dubois et al., 1956). Dried samples were extracted by adding $80 \%$ ethanol to a 100 -mg sample and incubated at room temperature overnight. The homogenate was centrifuged at $5000 \mathrm{rpm}$ for $5 \mathrm{~min}$. The supernatant was collected and the carbohydrates were liberated by hydrolysis with addition of $5 \%$ phenol (v/v) and $98 \%$ sulfuric acid (v/v) (Dubois et al., 1956). The optical density of the solution was then measured with an HP 8454A spectrophotometer (Agilent Technologies) at $490 \mathrm{~nm}$. For each sampling date, a standard curve was prepared from four concentrations of D-glucose, and a regression equation was established for the determination of carbohydrate concentrations in unknown samples.

Chlorophyll fluorescence. The chlorophyll fluorescence was measured six times between 1 July and 28 Aug. using a Hansatech Plant Efficiency Analyser (PEA) Model PEA KM2, from Hanstech Instrument Ltd. (Kings Lynn, U.K.). Chlorophyll fluorescence measurements were conducted midday (between 1200 and $14200 \mathrm{HR}$ ) for each of the sampling dates. Needles were placed into a clip and dark acclimated for a period of $15 \mathrm{~min}$, allowing all electron acceptors to fully oxidize then placed under the PEA to measure the $F_{\mathrm{v}} / F_{\mathrm{m}}$ parameter. Ten trees were measured in each plot for a total of 40 samples for all four replicates per treatment at each sampling date.

Data analysis. Morphological data were tested for homogeneity of variance and normality and analyzed for mean comparison by analysis of variance (ANOVA). A level of significance of $\alpha=0.05$ was used for inferring any statistical significance. When the model was significant, the least significant difference method with a Bonferroni correction at $P \leq 0.05$ was used to make pairwise comparisons between responses. Stem water potential, chlorophyll pigments, and chlorophyll fluorescence data were analyzed using the GLM procedure for repeated measures $(P \leq 0.05)$. For each sampling date, photosynthetic pigments, carbohydrate concentrations, and chlorophyll fluorescence were analyzed by the ANOVA procedure and mean separation as described previously. A correlation analysis between stem water potential and physiological parameters was conducted to determine the effect of drought stress on plant physiology. All statistical analyses were performed using Systat 13 statistical software (Systat Software, Inc., Chicago, IL).

\section{Results}

Stem water potential measurements. Plants from irrigated plots maintained higher $\Psi$ pd and $\Psi$ md compared with those from the control (drought) plots during the treatment period. Predawn water potential values recorded in plants from the control plots corresponded to early (16 June), middle (14 July), and late (11 Aug.) stages of drought reading, $-1.6,-1.4$, and $-1.8 \mathrm{Mpa}$, respectively. Predawn water potential in irrigation treatments showed large seasonal fluctuations, increasing slightly as the season advanced with a late-season separation between $3.7 \mathrm{~cm} /$ week and the other three irrigation treatments. Predawn stem water potential values were generally higher than midday measurements. Midday water potentials in the control treatment were at their lowest on 14 July $(-2.9 \mathrm{Mpa})$ and remained low throughout the season. For irrigated treatments, $\Psi$ md also decreased on 14 July but were otherwise relatively stable among the four irrigation treatments (Fig. 2).

Growth response. All growth response parameters were affected by water treatments. Irrigated treatments had significantly higher relative height growth compared with control treatments (Table 1). The difference in relative height growth between plants irrigated at $1.25,2.50$, and $3.70 \mathrm{~cm} /$ week was not significant. Relative root collar diameter growth values were similar to height growth with a significant difference between plants from irrigated treatments and control plants and no difference among the various irrigation treatments. Terminal shoot growth
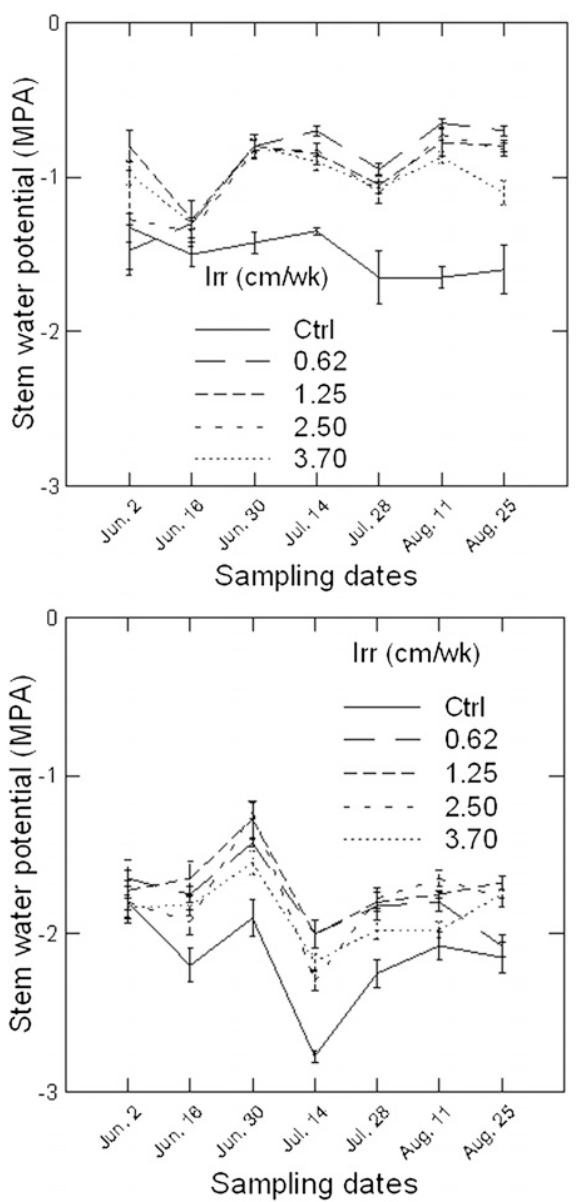

Fig. 2. Predawn and midday stem water potential as affected by various irrigation treatments. Bars indicate SES. The data were analyzed by the General Linear Model procedure for repeated measures. The model was significant for both the predawn $(P \leq 0.007)$ and midday. 
Table 1. Growth characteristics of $A$. fraseri under various irrigation treatments.

\begin{tabular}{lccr}
\hline $\begin{array}{l}\text { Irrigation treatments } \\
(\mathrm{cm} / \text { week })\end{array}$ & RHG $\left(\mathrm{cm} \cdot \mathrm{cm}^{-1}\right)$ & RRCD $\left(\mathrm{mm} \cdot \mathrm{mm}^{-1}\right)$ & \multicolumn{1}{c}{ TS $(\mathrm{cm})$} \\
\hline 0.00 & $0.36 \pm 0.02^{\mathrm{a}}$ & $0.24 \pm 0.02^{\mathrm{a}}$ & $8.41 \pm 0.7^{\mathrm{a}}$ \\
0.62 & $0.43 \pm 0.02^{\mathrm{b}}$ & $0.36 \pm 0.02^{\mathrm{b}}$ & $10.29^{\mathrm{b}} \pm 0.7^{\mathrm{a}}$ \\
1.25 & $0.56 \pm 0.03^{\mathrm{c}}$ & $0.36 \pm 0.01^{\mathrm{b}}$ & $16.59 \pm 1.1^{\mathrm{b}}$ \\
2.50 & $0.49 \pm 0.03^{\mathrm{c}}$ & $0.42 \pm 0.02^{\mathrm{b}}$ & $12.27^{\mathrm{b}} \pm 0.9^{\mathrm{a}}$ \\
3.70 & $0.58 \pm 0.02^{\mathrm{c}}$ & $0.36 \pm 0.02^{\mathrm{b}}$ & $15.95 \pm 0.9^{\mathrm{b}}$ \\
\hline
\end{tabular}

Number followed by the same letter indicates no statistical significant difference (Tukey's honestly significant difference test with $95 \%$ confidence).

$\mathrm{RHG}=$ relative height growth; $\mathrm{RRCD}=$ relative root collar diameter; $\mathrm{TS}=$ terminal shoot growth.

was also significantly affected by irrigation treatments with irrigated treatments significantly higher than control treatments (Table 1).

Photosynthetic pigments. There was a general midseason decrease in pigment content ( $\mathrm{Chl} \mathrm{a,} \mathrm{Chl} \mathrm{b}$, and carotenes) in predawn measurements. Chl a values were $0.75 \mathrm{mg} \cdot \mathrm{g}^{-1}$ or higher in the first measurements conducted on 2 June (Fig. 3). During the midseason measurements, $\mathrm{Chl}$ a values were generally lower than early-season measurements, and late-season (25 Aug.) values were much higher. Irrigated treatments had higher Chl a values in the late season compared with the non-irrigated treatment. Chl b values were generally lower than $\mathrm{Chl} \mathrm{a}$, measuring $0.4 \mathrm{mg} \cdot \mathrm{g}^{-1}$ in the early season, slightly decreasing in the middle of the season, and rising in the late season. However, except for the two highest irrigation treatments, the lateseason rise in $\mathrm{Chl} b$ values did not reach the early-season measurements. The total carotene concentration was generally similar to Chl measuring high in the early season, decreasing in the midseason, and rising in the late-season evaluation. Irrigated treatments also had higher carotenes content compared with control treatments in the late season. The carbohydrate concentrations in needles in predawn measurements also varied widely throughout the growing season, showing a midseason decrease and a strong rise at the end of the growing season (Fig. 3). Carbohydrate values were at their highest at the end of the season, and there was no statistical difference between treatments.

Midday measurements of photosynthetic pigments ( $\mathrm{Chl} \mathrm{a}, \mathrm{Chl} \mathrm{b}$, and carotenes) displayed a seasonal trend very similar to that obtained for predawn measurements. However, except for $\mathrm{Chl}$ a in the early season, photosynthetic pigments in midday measurements were influenced by irrigation treatments (Fig. 4). Midday carbohydrate concentrations were very similar to the predawn values and there was no clear response to irrigation treatments.

Chlorophyll fluorescence. Seasonal variation in Chl fluorescence was generally analogous to $\mathrm{Chl}$ pigments decreasing toward the middle of the season and increasing late in the season (Fig. 5). The $F_{\mathrm{v}} / F_{\mathrm{m}}$ response to irrigation treatments was significant with control treatments generally having lower $F_{\mathrm{v}} / F_{\mathrm{m}}$ values compared with irrigated treatments. There was no statistical difference among the various irrigation treatments.
Correlation analysis. Correlation analysis conducted to determine the relationship between predawn and midday stem water potential and plant physiological characteristics (Table 2) indicated statistically significant negative correlations with $\mathrm{Chl}(\mathrm{a}+\mathrm{b})$ and carotenes in both the predawn and midday measurements $[R=-0.532$ and -0.732 for $\mathrm{Chl}(\mathrm{a}+\mathrm{b})$ in predawn and midday sampling and -0.536 and -0.735 for predawn and midday carotenes measurements]. The carbohydrate concentration had a weak positive correlation with stem water potential in midseason predawn $(R=0.436)$ and midday $(R=0.341)$ measurements. All other correlation combinations were statistically nonsignificant (Table 2).

\section{Discussion}

In the present study, we tested a selected set of potential physiological and biochemical drought stress markers in Abies fraseri under different water intensities. Stem water potential was used as the primary indicator of water stress in tested plants. Predawn stem water potential was generally higher than midday water potential. The lower midday potential values have been related to stomatal closure induced by increases in evaporative demand in the atmosphere as is the case when the vapor pressure deficit is elevated in the middle of the day (Williams and Araujo, 2002). If stomatal closure occurs for extended periods during the day, this leads to depression in carbon assimilation and water loss through physiological mechanisms at both stomatal and chloroplastic levels (Williams and Araujo, 2002). Both predawn and midday potential showed similar seasonal fluctuations in all watering treatments. These seasonal variations have been previously observed for Tsuga canadensis (Tyree et al., 1978), Morisonia americana (Sobrado, 1986), and Quercus species (Lansac et al., 1994). In our study we propose that the midseason increase in stress was related to stages of phenological development. That period corresponds to the shoot elongation period, and trees kept their water potentials low so that lammas would grow. The overall increase in water potential during the late season can be attributed to the formation of winter buds. In this study, there was clear separation in stem water potential between irrigated plants and control specimens, but the difference among the various irrigation treatments was not significant. This indicates similarity in water stress levels between trees from irrigated plots for all four levels of water applied. Lower levels of irrigation resulted in reduced seedling relative height and relative root collar diameter increments. This was expected because one of the first morphological indicators of drought stress is decreased plant height, stem diameter, and total biomass (Monclus et al., 2006). This has been previously observed in several conifers including Norway spruce and Scots pine (Pichler and Oberhuber, 2007; Sudachkova et al., 2009).

In the present study, chlorophyll pigments and carotene concentrations were generally elevated early in the season (2 June), decreased during the peak of the growing season (14 July), and increased during lateseason sampling (25 Aug.). Late-season measurements of photosynthetic pigments were inversely correlated to stem water potential suggesting a plant structural response to drought stress. The high level of Chl pigments late in the season, as observed in the current study, can be regarded as a protective adaptive mechanism in stressed plants. There was a reduction in pigments in droughtexposed plants in both predawn and midday measurements. A drought-induced reduction in pigments was also previously reported in Populus przewaslskii and P. cathayana (Yin et al., 2009), Quercus coccifera and Q. ilex (Baquedano and Castillo, 2007) and Impatiens walleriana Hook, and Pelargonium hortorum L.H. Bailey (Chylinski et al., 2007). The decrease in Chl pigments under water stress may be a result of either slow synthesis or faster breakdown (Ashraf, 2003; Brett and Singer, 1973). Under excessive sunlight, the absorption capacity of leaf photons is reduced, thus preventing overexcitation of photosystems (Anderson et al., 1992; Munne-Bosch and Alegre, 2000). Carotenes can prevent Chl-photosensitized formation of ${ }^{1} \mathrm{O}_{2}$ by intercepting the $\mathrm{Chl}$ triplet states (Demmig-Adams and Adams, 1996). The decrease in carotene concentration suggests that drought stress caused marked oxidative stress (Lei et al., 2006).

The conventional knowledge of plant response to stress proposes that stomatal closure occurs to prevent hydraulic failure, causing the photosynthetic uptake of carbon to diminish and in turn a reduction in carbohydrate production (McDowell et al., 2008). However, unexpected accumulation of soluble carbohydrates in response to drought has been attributed to an imbalance resulting in growth being more sensitive than $\mathrm{CO}_{2}$ to water deficits (Guehl et al., 1993). In the present study, the total carbohydrate concentration was not significantly affected by the various water treatments. However, there was a midseason decrease in carbohydrate concentrations; this period corresponds to the time when trees are actively undergoing shoot elongation. On the other hand, the late-season accumulation of carbohydrates is synchronized with the late-season bud formation and thought to be associated with an increase in the volume of xylem sap and 

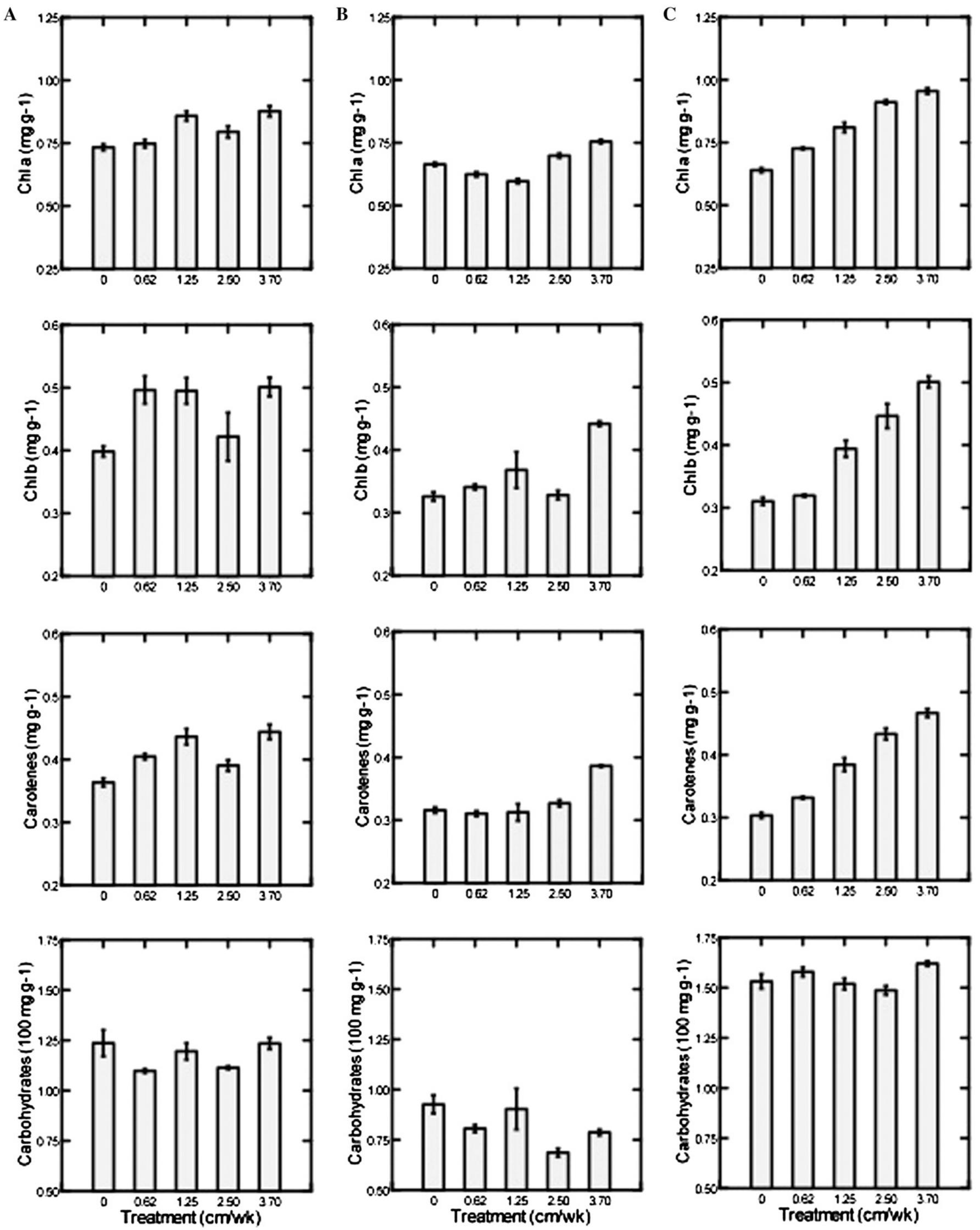

Fig. 3. Predawn chlorophyll (Chl) a, Chl b, carotenes, and carbohydrates measured at the beginning of the season on 2 June (A), middle of the season on 14 July (B), and end of the season on 25 Aug. $(\mathbf{C})$. Bars indicate SEs. $(P \leq 0.004)$ data. 

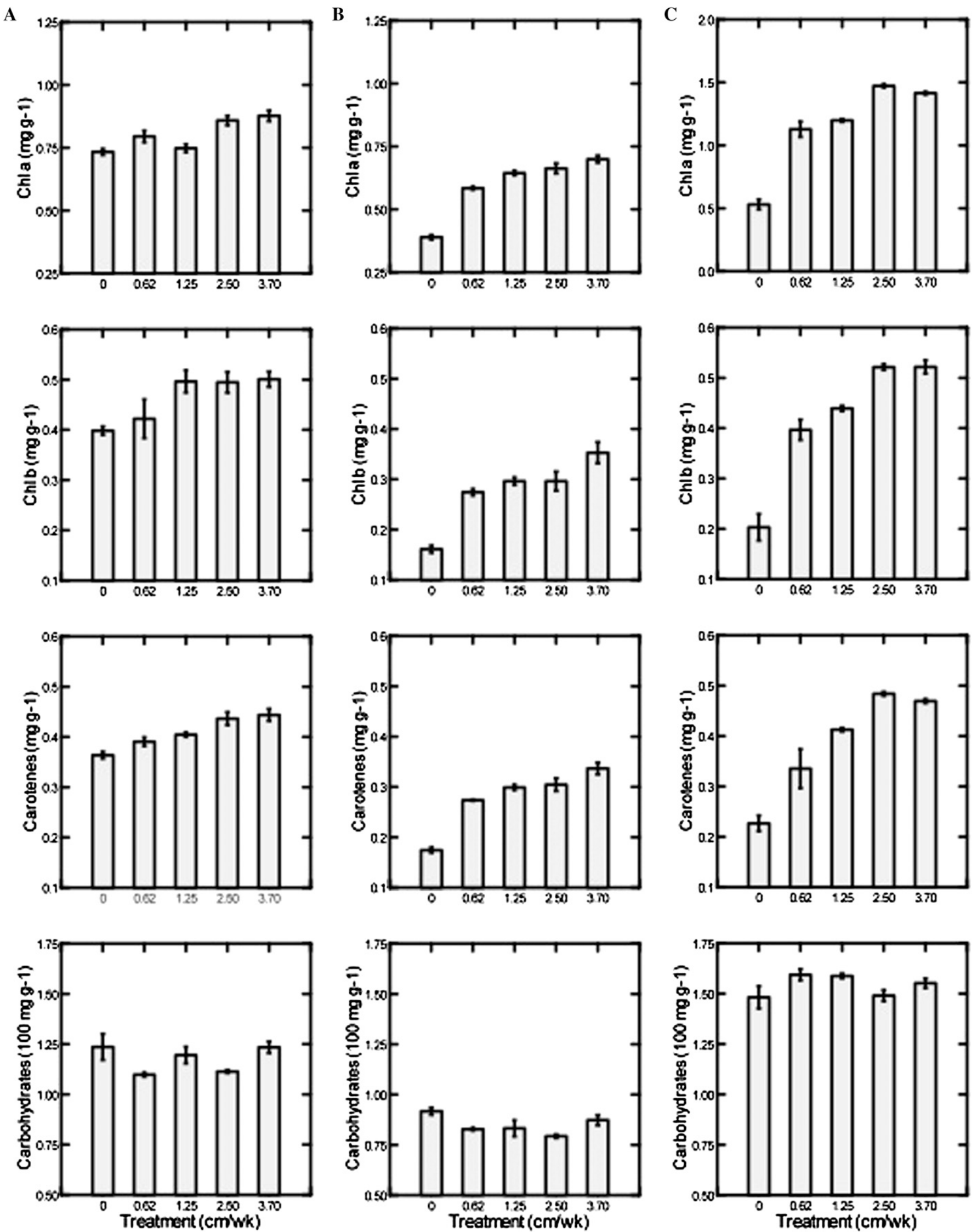

Fig. 4. Midday chlorophyll (Chl) a, Chl b, carotenes, and carbohydrates measured at the beginning of the season on 2 June (A), middle of the season on 14 July (B), and end of the season on 25 Aug. (C). Bars indicate sEs. 


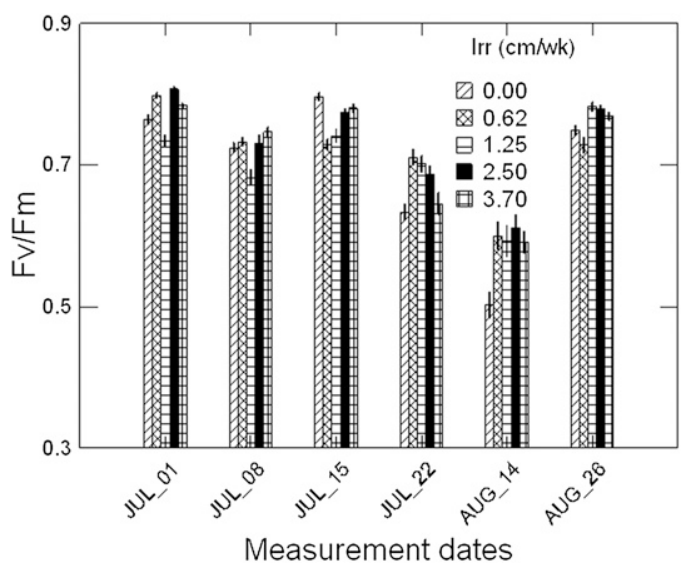

Fig. 5. Changes in chlorophyll fluorescence as affected by irrigation treatments. Bars indicate ses. The data were analyzed by the General Linear Modelunivariate repeated measures F-test. The model was significant $(P \leq 0.04)$.

Table 2. Pearson's correlation coefficient between predawn $(\Psi \mathrm{pd})$ and midday $(\Psi \mathrm{md})$ stem water potential, and corresponding photosynthetic pigments.

\begin{tabular}{|c|c|c|c|c|c|c|}
\hline & \multicolumn{6}{|c|}{ Predawn } \\
\hline & \multicolumn{2}{|c|}{2 June } & \multicolumn{2}{|c|}{14 July } & \multicolumn{2}{|c|}{25 Aug. } \\
\hline & $\Psi \mathrm{pd}$ & $P$ value & $\Psi \mathrm{pd}$ & $P$ value & $\Psi \mathrm{pd}$ & $P$ value \\
\hline Carbohydrates & -0.103 & 0.66 & 0.436 & 0.05 & 0.195 & 0.41 \\
\hline $\mathrm{Chl}(\mathrm{a}+\mathrm{b})$ & 0.241 & 0.30 & -0.310 & 0.18 & -0.532 & 0.02 \\
\hline \multirow[t]{4}{*}{ Carotenes } & 0.272 & 0.25 & -0.352 & 0.13 & -0.536 & 0.01 \\
\hline & \multicolumn{6}{|c|}{ Midday } \\
\hline & \multicolumn{2}{|c|}{2 June } & \multicolumn{2}{|c|}{14 July } & \multicolumn{2}{|c|}{25 Aug. } \\
\hline & Imd & $P$ value & Imd & $P$ value & Imd & $P$ value \\
\hline Carbohydrates & 0.329 & 0.16 & 0.341 & 0.14 & 0.017 & 0.94 \\
\hline $\mathrm{Chl}(\mathrm{a}+\mathrm{b})$ & 0.131 & 0.58 & -0.172 & 0.47 & -0.732 & 0.00 \\
\hline Carotenes & 0.113 & 0.63 & -0.171 & 0.47 & -0.735 & 0.00 \\
\hline
\end{tabular}

The data were analyzed by Pearson correlation using the Bartlett $\chi^{2}$ statistic $(\alpha=0.05)$ and a Bonferroni probability table.

$\mathrm{Chl}=$ chlorophyll

a decrease in parenchymal water content (Ameglio et al., 2004; Sakr et al., 2003). This phenomenon has been observed in other conifers (Hoch et al., 2003; Li et al., 2008). Overall, significant water stress effects were observed on photosynthetic pigments, but these changes were not enough to significantly affect the carbohydrate concentrations. This result suggests that water stress and all associated morphological and physiological effects observed in this study were not the result of carbon starvation or a reduction in availability of metabolic carbohydrates necessary for plant functions. Therefore, we can hypothesize that the main response mechanism observed in this study was through hydraulic failure, in which xylem conduits in stems and roots cavitate stopping the flow of water, desiccating tissues and leading to cellular death.

Implications for fraser fir production in drought-prone areas are rather serious especially because there is not much that can be done against xylem cavitation when a reduced soil water supply is coupled with an increase evaporative demand under droughty conditions.

\section{Conclusions}

This study investigated the effect of drought stress on growth, photosynthetic pigments, and carbohydrate concentrations in fraser fir. Drought stress significantly affected relative height growth, relative root collar diameter, and terminal shoot growth. Photosynthetic pigments were generally at their lowest in the midseason and increased late in the growing season. Drought stress results in reduced photosynthetic pigments either as a result of low synthesis or faster breakdown of pigments caused by an increase in the oxidative stresses induced. Changes in photosynthetic pigments were accompanied by similar changes in chlorophyll fluorescence. There was a large seasonal variation in carbohydrate concentrations related to the plant shoot elongation (midseason), replenishment of carbohydrate reserves, and decrease in parenchymal water content late in the season. Surprisingly, water stress did not significantly affect carbohydrate concentrations in this study. We concluded that significant effects observed on photosynthetic pigment concentrations did not affect carbohydrate concentrations. Therefore, we can assume that the short-term exposure of $A$. fraseri to water stress did not cause a reduction in supply of metabolic carbohydrates; therefore, mortality in water-stressed plans would be the result of hydraulic failure caused by xylem cavitation leading to cessation of water flow in tissues, desiccation, and cellular death. Further studies are needed to confirm these preliminary conclusions.

\section{Literature Cited}

Ameglio, T., M. Decourteix, G. Alves, V. Valentin, S. Sakr, J.L. Julien, G. Peter, A. Guilliot, and A. Lacointe. 2004. Temperature effects on xylem sap osmolarity in walnut trees: Evidence for a vitalistic model of winter embolism repair. Tree Physiol. 24:785-793.

Anderson, J.V., B.I. Chevone, and J.L. Hess. 1992 Seasonal-variation in the antioxidant system of eastern white-pine needles-Evidence for thermal-dependence. Plant Physiol. 98:501-508.

Ashraf, M. 2003. Relationships between leaf gas exchange characteristics and growth of differently adapted populations of Blue panic grass (Panicum antidotale Retz.) under salinity or waterlogging. Plant Sci. 165:69-75.

Baquedano, F.J. and F.J. Castillo. 2007. Drought tolerance in the Mediterranean species Quercus coccifera, Quercus ilex, Pinus halepensis, and Juniperus phoenicea. Photosynthetica 45:229238.

Beck, D.E. 1990. Abies fraseri (Pursh) Poir. Fraser fir, p. 47-51. In: Burns, R.M. and B.H. Honkala (eds.). Silvics of North America. Vol. 1. Conifers. Agric. Handb. 654. U.S. Department of Agriculture, Forest Service, Washington, DC.

Brett, W.J. and A.C. Singer. 1973. Chlorophyll concentration in leaves of Juniperus-virginiana L-Measured over a 2-year period. Amer. Midl. Nat. 90:194-200.

Bunce, J.A. 1981. Relationships between maximum photosynthetic rates and photosynthetic tolerance of low leaf water potentials. Can. J. Bot. 59:769-774.

Chylinski, W.K., A.J. Lukaszewska, and K. Kutnik. 2007. Drought response of two bedding plants. Acta Physiol. Plant. 29:399-406.

Deltoro, V.I., A. Calatayud, C. Gimeno, A. Abadia, and E. Barreno. 1998. Changes in chlorophyll a fluorescence, photosynthetic $\mathrm{CO}_{2}$ assimilation and xanthophyll cycle interconversions during dehydration in desiccation-tolerant and intolerant liverworts. Planta 207:224-228.

Demmig-Adams, B. and W.W. Adams. 1996. The role of xanthophyll cycle carotenoids in the protection of photosynthesis. Trends Plant Sci. 1:21-26.

Dubey, R.S. 1997. Photosynthesis in plants under stressful conditions, p. 859-875. In: Pessarakli, M. (ed.). Handbook of photosynthesis. Marcel Dekker, New York, NY.

Dubois, M., K.A. Gilles, J.K. Hamilton, P.A. Rebers, and F. Smith. 1956. Colorimetric method for the determination of sugars and related substances. Annals of Chemistry 28:350-356.

Farquhar, G.D., S. von Caemmerer, and J.A. Berry. 2001. Models of photosynthesis. Plant Physiol. 125:42-45.

Gollan, Y., J.B. Passioura, and R. Munns. 1986 Soil water status affects the stomatal conductance of fully turgid wheat and sunflower leaves. Aust. J. Plant Physiol. 48:575-579.

Guehl, J.M., A. Clement, P. Kaushal, and G. Aussenac. 1993. Planting stress, water status and nonstructural carbohydrate concentrations in Corsican pine seedlings. Tree Physiol. 12:173-183.

Hartung, W. 1983. The site of action of abscisic acid at the guard cell plasmalemma of Valerianella locusta. Plant Cell Environ. 6:427-428.

Hoch, G., A. Richter, and C. Korner. 2003. Nonstructural carbon compounds in temperate forest trees. Plant Cell Environ. 26:1067-1081.

Jaleel, C.A., R. Gopi, P. Manivannan, M. Gomathinayagam, H.B. Shao, C.X. Zhao, and R. Panneerselvam. 2008. Endogenous 
hormonal and enzymatic responses of Catharanthus roseus with triadimefon application under water deficits. C. R. Biol. 331:844-852.

Kameli, A. and D.M. Losel. 1996. Growth and sugar accumulation in durum wheat plants under water stress. New Phytol. 132:57-62.

Lansac, A.R., J.P. Zaballos, and A. Martin. 1994. Seasonal water potential changes and proline accumulation in Mediterranean shrubland species. Vegetation 113:141-154.

Lei, Y., C. Yin, and C. Li. 2006. Differences in some morphological, physiological, and biochemical responses to drought stress in two contrasting populations of Populus przewalskii. Plant Physiol. 127:182-191.

Li, M.H., W.F. Xiao, S.G. Wang, G.W. Cheng, P. Cherubini, X.H. Cai, X.L. Liu, X.D. Wang, and W.Z. Zhu. 2008. Mobile carbohydrates in Himalayan treeline trees. Evidence for carbon gain limitation but not for growth limitation. Tree Physiol. 28:1287-1296.

McDowell, N., W.T. Pockman, C.D. Allen, D.D. Breshears, N. Cobb, T. Kolb, J. Plaut, J. Sperry, A. West, D.G. Williams, and E.A. Yepez. 2008. Mechanisms of plant survival and mortality during drought: Why do some plants survive while others succumb to drought? New Phytol. 178:719-739.

Monclus, R., E. Dreyer, M. Villar, F.M. Delmotte, D. Delay, J.M. Petit, C. Barbaroux, D. Thiec, C. Brechet, and F. Brignolas. 2006. Impact of drought on productivity and water use efficiency in 29 genotypes of Populus deltoides $\times$ Populus nigra. New Phytol. 169:765-777.

Munne-Bosch, S. and L. Alegre. 2000. Changes in carotenoids, tocopherols and diterpenes during drought and recovery, and the biological significance of chlorophyll loss in Rosmarinus officinalis plants. Planta 210:925-931.

Nar, H., A. Saglam, R. Terzi, Z. Varkonyi, and A. Kadioglu. 2009. Leaf rolling and photosystem II efficiency in Ctenanthe setosa exposed to drought stress. Photosynthetica 47:429-436.
Nzokou, P. and L.A. Leefers. 2007. Costs and returns in Michigan Christmas tree production. Great Lakes Christmas Trees Journal 2:11-16.

Pichler, P. and W. Oberhuber. 2007. Radial growth response of coniferous forest trees in an inner Alpine environment to heat-wave in 2003. For. Ecol. Mgt. 242:688-699.

Pukacki, P.M. and E. Kaminska-Rozek. 2005. Effect of drought stress on chlorophyll a fluorescence and electrical admittance of shoots in Norway spruce seedlings. Trees (Berl.) 19: 539-544.

Ribeiro, R.V., E.C. Machado, M.G. Santos, and R.F. Oliveira. 2009. Seasonal and diurnal changes in photosynthetic limitation of young sweet orange trees. Environ. Exp. Bot. 66:203211.

Sakr, S., G. Alves, R.L. Morillon, K. Maurel, M. Decourteix, A. Guilliot, P. Fleurat-Lessard, J.L. Julien, and M.J. Chrispeels. 2003. Plasma membrane aquaporins are involved in winter embolism recovery in walnut tree. Plant Physiol. 133:630-641.

Schwab, K.B., U. Schreiber, and U. Heber. 1989. Response of photosynthesis and respiration of resurrection plants to desiccation and rehydration. Planta 177:217-227.

Shope, J.C., D. Peak, and K.A. Mott. 2008. Stomatal responses to humidity in isolated epidermes. Plant Cell Environ. 31:1290-1298.

Sobrado, M.A. 1986. Aspects of tissue water relations and seasonal changes of leaf water potential components of evergreen and deciduous species coexisting in tropical dry forests. Oecologia 68:413-416.

Sudachkova, N.E., I.L. Milyutina, and L.I. Romanova. 2009. Adaptive responses of scots pine to the impact of adverse abiotic factors on the rhizosphere. Russ. J. Ecol. 40:387-392.

Terzi, R., A. Sağlam, H. Kutlu, H. Nar, and A. Kadioğlu. 2010. Impact of soil drought stress on photochemical efficiency of photosystem II and antioxidant enzyme activities of Phaseolus vulgaris cultivars. Turk. J. Bot. 34:1-10.
Thomas, H. 1990. Osmotic adjustment in Lolium perenne-Its heritability and the nature of solute accumulation. Ann. Bot. (Lond.) 66: 521-530.

Tuba, Z., H.K. Lichtenthaler, Z.S. Csintalan, Z. Nagy, and K. Szente. 1996. Loss of chlorophylls, cessation of photosynthetic $\mathrm{CO}_{2}$ assimilation and respiration in the poikilochlorophyllous plant Xerophyta scabrida during desiccation. Physiol. Plant. 96:3383-3388.

Turner, N.C. 1988. Measurement of plant water status by the pressure chamber technique. Irrig. Sci. 9:289-308.

Tyree, M.T., Y.N.S. Cheung, M.E. Macgregor, and A.J.B. Talbot. 1978. Characteristics of seasonal and ontogenetic changes in tissue-water relations of Acer, Populus, Tsuga, and Picea. Can. J. Bot. 56:635-647.

Vassey, T.L. and T.D. Sharkey. 1989. Mild water stress of Phaseolus vulgaris plants leads to reduced starch synthesis and extractable sucrose phosphate synthase activity. Plant Physiol. 89:1066-1070.

Wellburn, A.R., I. Gounaris, L. Fassler, and H.K. Lichtenthaler. 1983. Changes in plastid ultrastructure and fluctuations of cellular isoprenoid and carbohydrate coumpounds during continued etiolation of dark-grown oat seedlings. Physiol. Plant. 59:347-354

Williams, L.E. and F.J. Araujo. 2002. Correlations among predawn leaf, midday leaf, and midday stem water potential and their correlations with other measures of soil and plant water status in Vitis vinifera. J. Amer. Soc. Hort. Sci. 127:448454.

Yin, C.Y., X.Y. Pang, and Y.B. Lei. 2009. Populus from high altitude has more efficient protective mechanisms under water stress than from lowaltitude habitats: A study in greenhouse for cuttings. Physiol. Plant. 137:22-35.

Yordanov, I., V. Velikova, and T. Tsonev. 2000. Plant responses to drought, acclimation, and stress tolerance. Photosynthetica 38:171185 . 